\title{
DIÁLOGO ENTRE CINEMA E EDUCAÇÃO AMBIENTAL
}

\author{
Marcelo Igor Araújo Cabral ${ }^{1}$ \\ Eliane Maria de Souza Nogueira ${ }^{2}$
}

Resumo: A Educação Ambiental carece de meios para diversificar a sua prática, e encontra na linguagem cinematográfica elementos para ampliar os olhares sobre o ecossistema. Este trabalhou reúne publicações que discutem a relação entre animações e Educação Ambiental, resultado de pesquisa exploratória e qualitativa, baseada em buscas em bancos de indexação. Foram publicadas 44 obras em bibliotecas virtuais entre 2007 e 2018 (22 artigos, 10 dissertações, 6 monografias e 5 resumos), demonstrando expressiva quantidade de trabalhos que estudam a importância do cinema de animação para a Educação Ambiental. Este estudo evidenciou que o filme do gênero animação é capaz de enriquecer a prática pedagógica e fomentar reflexões, quando a sua linguagem é cuidadosamente explorada no contexto da situação didática.

Palavras-chave: Filmes; Animação; Meio Ambiente.

1 Universidade do Estado da Bahia. E-mail: marcelloigor@yahoo.com.br

2 Universidade do Estado da Bahia. E-mail: emsnogueira@yahoo.com.br

Revbea, São Paulo, V. 14, № 4: 106-119, 2019. 


\section{Introdução}

A demanda por ferramentas para instrumentalizar e enriquecer a prática pedagógica exige dos educadores criatividade e habilidade na apropriação das diversas possibilidades que a tecnologia proporciona. O que não é diferente no campo da Educação Ambiental, ao demandar caminhos metodológicos inovadores para promover reflexões sobre a relação da humanidade com o ambiente, e encontrar nas produções cinematográficas e na linguagem utilizada por elas instrumentos que contribuem para a compreensão das relações ecológicas em que o ser humano está inserido. Ampliando os olhares das pessoas sobre essas relações, buscando por mudanças de postura, redução de impactos e, consequentemente, convivência harmoniosa com os demais fatores que integram o ecossistema.

Nessa perspectiva, Esperança e Dias (2008) alertam que o contato com as diferentes tecnologias mudou drasticamente os modos de compartilhamento e acesso ao conhecimento, e sugerem que é preciso repensar a educação, uma vez que tais tecnologias configuram-se como instrumentos pedagógicos, que podem atingir o público de diferentes modos, alertando para a necessidade de conscientizar-se que a linguagem audiovisual faz parte do cotidiano, e que as mídias estão presentes de maneira muito mais profunda nas experiências extraescolares das crianças. Atrelado a isso, Silva et al. (2017) consideram que o cinema, assim como outras expressões da arte, como a música e a literatura são capazes de ampliar os olhares sobre a importância do ensino de ciências e dos avanços tecnológicos na sociedade, pois funciona como uma ferramenta que alia arte e educação.

A cinematografia mundial possui diversos exemplos de filmes de animação que promovem reflexões sobre questões ambientais e sobre os impactos de ordem antrópica nos ecossistemas naturais. Bambi (1942), Mogli - o menino lobo (1967), O Rei Leão (1994), Pocahontas (1995), 101 Dalmatas (1996), Vida de Inseto (1998), Tarzan (1999), A Era do Gelo (2002; 2006; 2009; 2012; 2016), Procurando Nemo (2003), Irmão Urso (2003), Happy Feet - o pinguim (2006), Os sem floresta (2006), Bee Movie: a história de uma abelha (2007), Avatar (2009), Wall-E (2008), Rio (2011; 2014), Lórax: em busca da trúfula perdida (2012) e Madagascar $(2005$; 2008; 2012; 2014; 2018) são obras onde é possível observar potencial para a Educação Ambiental nos seus roteiros.

Levando em consideração a importância da linguagem cinematográfica enquanto instrumento pedagógico, este ensaio buscou quantificar as publicações que exploram discussões sobre as relações entre cinema de animação e Educação Ambiental, e compreender como esses temas dialogam entre si no sentindo de ampliar as possibilidades da prática pedagógica com esse direcionamento. A partir de estudo exploratório e qualitativo (MARCONI; LAKATOS, 2011), fundamentando-se na busca por publicações em bancos de indexação como Google Acadêmico e Scielo, delimitou-se a pesquisa a partir das palavras cinema, filmes de animação e Educação Ambiental, que direcionaram as buscas para periódicos ou repositórios de Universidades. Após análise dos resultados, foram consideradas todas as publicações de 2007 as

revista brasileira educação ambiental 
2018 que discutem o relacionamento entre cinema e educação, sob aspectos como percepção de educandos e educadores sobre o uso dos filmes, potencialidades pedagógicas, análise dos conteúdos, fidelidade à linguagem científica, erros conceituais, aspectos morfológicos e comportamentais de espécies.

\section{Filmes de animação}

Os avanços tecnológicos proporcionaram o surgimento de novas formas de comunicação ou aprimoramento daquelas já existentes, e com o cinema de animação não foi diferente, sendo resultante do desenvolvimento de sistemas culturais que 0 antecederam, possibilitando uma linguagem que agrega diversas ferramentas e enriquecem o processo comunicativo, como códigos verbais, visuais, sonoros e sinestésicos e são capazes de estimular os sentidos (GOMES; SANTOS, 2007).

O gênero cinematográfico de animação está presente na vida e imaginário das pessoas, em função do potencial que tem seus enredos e personagens de estabelecer conexões afetivas com o público consumidor. Nessa perspectiva, Esperança e Dias (2008) afirmam que as produções audiovisuais impactam sobre o desenvolvimento cultural infantil, pois ao consumir produtos midiáticos, as crianças estabelecem vínculos com os personagens que passam a fazer parte do seu cotidiano. E segundo Franco et al. (2013), os autores, desenhistas e produtores de filmes de animação contribuem efetivamente com isso, pois preocupam-se em inserir elementos que induzam à identificação com os espectadores.

As obras cinematográficas têm liberdade para criar e recriar ambientes organizados simbolicamente de acordo com as suas perspectivas, mas que não são descontextualizados nem anulam o diálogo com a realidade em que estão inseridos os seus espectadores (ALMEIDA, 2018). Sendo assim, por considerar a aceitação e percebendo o crescimento desse gênero, estúdios têm investido em tecnologia, qualidade dos aspectos gráficos e diversidade de roteiros, para que as produções ampliem seus horizontes, transcendendo barreiras etárias e conquistem outros públicos, passando a ser consumidas por indivíduos de todas as idades.

Nos últimos anos as películas de animação deixaram de agradar apenas o público infanto-juvenil e estão sendo consumidos por todas as faixas etárias, e segundo Gomes e Santos (2007), isso se deve ao fato de que formatos anteriores declinaram e a possibilidade de ampliar o seu público fez com que as animações nos dias de hoje apresentem trajetórias fílmicas mais robustas, diversificadas, capazes de explorar recursos como paródias, sátiras e a inserção de personagens com diversos perfis numa mesma obra, garantindo aceitação de uma parcela mais significativa dos espectadores.

Nesse sentido, Guimarães e Fantin (2016) defendem que o cinema de 
pessoas, pois tem caráter pedagógico, faz pensar e é importante fonte de conhecimento, levando em consideração que o mesmo influencia sobre a construção de identidades sociais e culturais. Em contrapartida, Penteado et al. (2018) alertam para importância do cinema de animação no que diz respeito à construção de imaginários sociais e a sua apresentação para crianças e adolescentes, que por outro lado, podem contribuir com a alienação e perpetuação de estereótipos, padronizações e caricaturização dos corpos humanos.

\section{Cinema de animação e o seu potencial pedagógico}

A compreensão da importância do uso da linguagem cinematográfica e sua relação com a educação é bem explicada por Guido e Bruzzo (2011) quando afirmam que

A potencialidade do cinema como forma de diversão popular e o fascínio despertado pelas imagens em movimento desde o início foram percebidos pelos produtores de filmes e pelos governos resultando em investimentos na direção do aproveitamento educativo do cinema. A percepção do potencial da imagem como instrumento de educação é anterior ao cinema. Os séculos que antecederam à invenção do cinematógrafo exploraram diversas possibilidades com as lanternas mágicas, que combinavam as imagens fixas com efeitos luminosos e sonoros. Os educadores e políticos de diversos países, épocas e tendências exploraram e promoveram a produção de películas segundo variados entendimentos do que é adequado e educativo.

A introdução do cinema de animação no contexto da prática pedagógica em Educação Ambiental enriquece o processo ensino-aprendizagem ao se apropriar de um elemento que faz parte do cotidiano de crianças, jovens e adultos, por isso Ihes é familiar. Da-silva e Coelho (2016) completam esse pensamento ao afirmarem que "a introdução da cultura pop na didática curricular traz para a sala de aula debates espontâneos, a partir de observações comparativas entre ficção e realidade, criando uma maior intimidade do aluno com o objeto de estudo. Essa iniciativa estimula a leitura, a pesquisa além dos livros didáticos, o senso crítico, a criatividade, os debates extracurriculares, a paixão por novas descobertas, a satisfação individual e a curiosidade para além dos muros da escola. Tais estímulos são benéficos, influenciando diretamente no desenvolvimento acadêmico, cultural e pessoal do aluno".

O uso de recursos audiovisuais pode instrumentalizar a situação didática, servindo de subsídio para fomentar discussões, em razão da sua aceitação e inserção no dia a dia de um público cada vez mais diversificado. Da-silva e Coelho (2016) consideram que "HQ, livros, filmes, desenhos animados e séries de TV podem ser utilizados em todos os níveis e disciplinas acadêmicos. Com base nas mídias, muitos conceitos biológicos podem ser 
trabalhados em aulas regulares com a devida adequação de nível de profundidade; há conteúdos passíveis de aplicação tanto no ensino superior quanto no fundamental e médio." Atrelado a isso, Oliveira et al. (2016), enfatizam que as produções cinematográficas do gênero animação fazem parte do cotidiano de crianças e adolescentes, e diante da necessidade de concepção e inovação de métodos pedagógicos, podem servir à educação em qualquer espaço formativo e para qualquer público ou faixa etária, por ser ferramenta de fácil acesso e aceitação.

Bastiani e Rosa (2012) defendem que a linguagem cinematográfica é importante ferramenta pedagógica até mesmo nos anos finais da educação básica, dado o seu grau de interdisciplinaridade, e aponta que o uso do cinema não deve ser descontextualizado, mas a sua inserção na prática deve ser processual e coordenada com sensibilização anterior à sua exibição, seguida de análise e discussão das temáticas abordadas na película. Pensamento corroborado por Barros et al. (2013), ao lembrarem que o cinema se torna uma ferramenta importante no processo ensino-aprendizagem, quando o mesmo é utilizado de maneira planejada, a partir da apropriação da linguagem, abordagens $\mathrm{e}$ intencionalidades do filme escolhido, pelo educador. $\mathrm{E}$ complementado por Santos e Piassi (2010), quando afirmam que ao selecionar uma obra o educador precisa investir tempo, para que se faça uma análise criteriosa do seu conteúdo, de modo que a linguagem seja adequada à faixa etária dos educandos e os objetivos pretendidos sejam alcançados.

Diante disso, é possível considerar que a película agrega valor ao planejamento pedagógico em Educação Ambiental, mas a prática não deve reduzir-se a esse instrumento e ao seu conteúdo, além do fato de que a obra não pode ter direcionamento moralista, mas fomentar reflexão. Sobre isso, Guido e Bruzzo (2011) concluem que não é possível perder a essência do cinema como forma de expressão e questionamento da condição humana, o objetivo da produção das obras e o seu uso não é somente persuadir, mas provocar debates efetivos sobre o nosso relacionamento com os recursos naturais e o desafio de pensar o seu usufruto de modo sustentável. Enquanto Anjos e Santos (2017) completam que o uso de filmes pode possibilitar uma abordagem mais atrativa e chamam a atenção para o fato de que os filmes de animação não são produzidos para fins pedagógicos e sim comerciais, por isso cabe ao educador avaliá-los antes de sua utilização no processo educativo.

\section{Publicações que discutem a relação entre cinema e Educação Ambiental}

Documentos que auxiliem o educador na busca por instrumentos pedagógicos que possam referenciar e contribuir com a sua prática são de grande valor atualmente. Livros, guias, artigos científicos que contribuem com ampliação das ferramentas disponíveis para o educador ambiental possibilitam a diversificação das metodologias e roteiros didáticos, ampliando também as possibilidades de efetivação dos objetivos definidos ao planejar uma situação de aprendizagem. 
No tocante as produções relativas aos filmes de animação com abordagem ambiental, foram inventariadas 44 obras, distribuídas em 23 artigos, 10 dissertações, 6 monografias e 5 resumos expandidos publicados em anais de eventos científicos (Quadro 1). As publicações pesquisadas estão elencadas obedecendo a sua ordem cronológica de publicação, acompanhadas dos seus autores, formatos de comunicação científica e ano de publicação ou finalização, para aqueles que não foram publicados.

Quadro 1: Produção científica sobre animação e Educação Ambiental entre 2007 e 2018.

\begin{tabular}{|c|c|c|c|}
\hline $\begin{array}{l}\text { Título da publicação } \\
\text { O Double Coding na Animação: A Construção do Desenho } \\
\text { Animado Contemporâneo para Adultos e Crianças }\end{array}$ & Formato & $\begin{array}{l}\text { Autores } \\
\text { GOMES e } \\
\text { SANTOS }\end{array}$ & Ano \\
\hline $\begin{array}{l}\text { A narrativa cinematográfica alegórica/simbólica no cinema de } \\
\text { animação }\end{array}$ & $\mathrm{D}$ & FERREIRA & 2007 \\
\hline $\begin{array}{l}\text { Filmes de ficção científica como mediadores de conceitos } \\
\text { relativos ao meio ambiente }\end{array}$ & A & MACHADO & 2008 \\
\hline $\begin{array}{l}\text { Uso do desenho animado como estratégia metodológica para a } \\
\text { Educação Ambiental }\end{array}$ & $\mathrm{D}$ & XAVIER & 2008 \\
\hline $\begin{array}{l}\text { Ficção científica e ensino de ciências: para além do método de } \\
\text { 'encontrar erros em filmes' }\end{array}$ & A & $\begin{array}{c}\text { PIASSI e } \\
\text { PIETROCOLA }\end{array}$ & 2009 \\
\hline $\begin{array}{l}\text { Um Pedido de Socorro do Planeta Terra: Cinema de animação e } \\
\text { Educação Ambiental }\end{array}$ & A & LUVIELMO & 2009 \\
\hline $\begin{array}{l}\text { A utilização didática do cinema para a aprendizagem da } \\
\text { Educação Ambiental }\end{array}$ & $\mathrm{D}$ & LEIVAS & 2009 \\
\hline $\begin{array}{l}\text { "WALL-E": O uso de um filme de animação na Educação } \\
\text { Ambiental com temas transversais dos PCN }\end{array}$ & A & VIEIRA & 2010 \\
\hline $\begin{array}{l}\text { Filmes de animação como recurso didático: Uma proposta para o } \\
\text { professor }\end{array}$ & M & SANTOS & 2010 \\
\hline $\begin{array}{l}\text { Ficção ou realidade: uma perspectiva do futuro do nosso planeta } \\
\text { na visão infantil }\end{array}$ & A & PIASSI & 2010 \\
\hline $\begin{array}{l}\text { A Utilização dos Filmes de Animação "Procurando o Nemo", "Os } \\
\text { Sem Floresta" e "Vida de Inseto" como Recursos Didáticos no } \\
\text { Ensino de Ciências }\end{array}$ & $\bar{M}$ & ABREU & 2010 \\
\hline O cinema como componente didático da Educação Ambiental & A & OTT e CANDÉO & 2011 \\
\hline $\begin{array}{l}\text { Apontamentos sobre o cinema ambiental: a invenção de um } \\
\text { gênero e a Educação Ambiental }\end{array}$ & A & ARDENTE & 2011 \\
\hline $\begin{array}{l}\text { Educação Ambiental, cinema e biopoder: Uma discussão } \\
\text { possível. }\end{array}$ & $\mathrm{D}$ & VIEIRA & 2011 \\
\hline $\begin{array}{l}\text { Discutindo a Educação Ambiental em sala de aula sob o viés do } \\
\text { filme Wall-E }\end{array}$ & $\mathrm{R}$ & ROSSO & 2012 \\
\hline $\begin{array}{l}\text { Ética e cinema: uma proposta interdisciplinar para a Educação } \\
\text { Ambiental }\end{array}$ & A & GUIDO & 2012 \\
\hline Filmes nas salas de aula: as ciências em foco & $\mathrm{M}$ & BRUZZO & 2012 \\
\hline O uso do desenho animado como recurso didático - Filme Rio & $\bar{M}$ & LUVIELMO & 2012 \\
\hline $\begin{array}{l}\text { Debates sobre filmes infantis em sala de aula: uma ferramenta } \\
\text { contra a posse de animais silvestres }\end{array}$ & A & $\begin{array}{l}\text { FRIEDRICH e } \\
\text { SANTOS }\end{array}$ & 2013 \\
\hline $\begin{array}{l}\text { O uso do cinema como estratégia pedagógica para o ensino de } \\
\text { ciências e de biologia o que pensam alguns professores da } \\
\text { região metropolitana de Belo Horizonte }\end{array}$ & A & $\begin{array}{l}\text { BASTIANI e } \\
\text { ROSA }\end{array}$ & 2013 \\
\hline $\begin{array}{l}\text { Kenta Takada - Arrival of the insect movie stars: Commentary on } \\
\text { the animated movie "A Bug's Life" from the aspect of Cultural } \\
\text { Entomology providing insight for instruction of entomological } \\
\text { know ledge, insect conservation and management practic }\end{array}$ & $\mathrm{R}$ & SOUZA & 2013 \\
\hline $\begin{array}{l}\text { A entomologia no cinema: análise do filme Vida de Inseto } \\
\text { enquanto recurso didático }\end{array}$ & A & LISBOA & 2013 \\
\hline
\end{tabular}




\begin{tabular}{|c|c|c|c|}
\hline Título da publicação & Formato & Autores & Ano \\
\hline $\begin{array}{l}\text { Aspectos morfológicos, biológicos e comportamentais de insetos: } \\
\text { entre a literatura entomológica e a recriação fílmica }\end{array}$ & A & PINHEIRO & 2013 \\
\hline $\begin{array}{l}\text { Filmes de animação infantil como ferramenta de Educação } \\
\text { Ambiental }\end{array}$ & $\bar{M}$ & KINDEL & 2013 \\
\hline $\begin{array}{l}\text { Manual de orientações: o filme como recurso didático nas aulas } \\
\text { de ecologia }\end{array}$ & $\mathrm{D}$ & BARROS & 2013 \\
\hline $\begin{array}{l}\text { "Reflexões sobre cinema ambiental: uma abordagem } \\
\text { multidisciplinar" }\end{array}$ & $\mathrm{D}$ & $\begin{array}{l}\text { GIRASSOLE e } \\
\text { ZANELLA }\end{array}$ & 2013 \\
\hline $\begin{array}{l}\text { Ecologização e convivialidade: aproximações entre a Educação } \\
\text { Ambiental e o cinema }\end{array}$ & $\mathrm{D}$ & TAKADA & 2014 \\
\hline $\begin{array}{l}\text { Luz, câmera, ação: o uso de filmes como estratégia para o } \\
\text { ensino de Ciências e Biologia }\end{array}$ & A & FRANCO & 2014 \\
\hline Os filmes e os estudos de Educação Ambiental & $\mathrm{R}$ & SANTANA-REIS & 2014 \\
\hline $\begin{array}{l}\text { Animais humanos ou humanos animais? Um estudo sobre a } \\
\text { representação dos animais antropomorfizados nos filmes de } \\
\text { animação }\end{array}$ & $\mathrm{D}$ & VIZACHRI & 2014 \\
\hline $\begin{array}{l}\text { A semente de trúfula no solo da educação geográfica: } \\
\text { pensamento ambiental e o cuidado com a terra em "The Lorax" } \\
\text { de Dr. Seuss. }\end{array}$ & A & NETO & 2015 \\
\hline O meio ambiente no filme infantil & $R$ & $\begin{array}{c}\text { REIS e } \\
\text { CARVALHO }\end{array}$ & 2015 \\
\hline O uso do filme Wall-E para o trabalho com Educação Ambiental & $\mathrm{R}$ & SILVA & 2015 \\
\hline $\begin{array}{l}\text { Percepções de estudantes do Ensino Médio noturno sobre } \\
\text { representações de animais em desenhos animados }\end{array}$ & $\mathrm{M}$ & $\begin{array}{l}\text { OLIVEIRA e } \\
\text { HÖMANSEDER }\end{array}$ & 2015 \\
\hline $\begin{array}{l}\text { Análise do filme de animação "vida de inseto" à luz da biologia } \\
\text { animal }\end{array}$ & A & $\begin{array}{l}\text { DA-SILVA e } \\
\text { COELHO }\end{array}$ & 2016 \\
\hline $\begin{array}{l}\text { Zoologia cultural, com ênfase na presença de personagens } \\
\text { inspirados em artrópodes na cultura pop }\end{array}$ & A & $\begin{array}{l}\text { DA-SILVA e } \\
\text { COELHO }\end{array}$ & 2016 \\
\hline O Cinema e os filmes de animação em Contextos formativos & A & $\begin{array}{l}\text { GUIMARÃES e } \\
\text { FANTIN }\end{array}$ & 2016 \\
\hline $\begin{array}{l}\text { Fantasia versus realidade: explorando as potencialidades do } \\
\text { cinema para o ensino de Ciências e Biologia }\end{array}$ & A & $\begin{array}{l}\text { COSTA e } \\
\text { BARROS }\end{array}$ & 2016 \\
\hline $\begin{array}{l}\text { Potencialidades pedagógicas do filme Bambi no ensino de } \\
\text { ecologia e Educação Ambiental }\end{array}$ & A & $\begin{array}{l}\text { SANTOS e } \\
\text { ANJOS }\end{array}$ & 2017 \\
\hline $\begin{array}{l}\text { As questões sociocientíficas e a trama do filme Elysium: } \\
\text { conexões entre ciência e cidadania no "chão da escola" }\end{array}$ & A & SILVA et al & 2017 \\
\hline $\begin{array}{l}\text { Educomunicação: um Estudo do Desenho de Dr. Seuss - O } \\
\text { Lorax - Em Busca da Trúfula Perdida - Metáfora do Aproximar } \\
\text { Homem e Natureza }\end{array}$ & A & HOPPE & 2017 \\
\hline $\begin{array}{l}\text { O cinema como instrumento de sensibilização ambiental para } \\
\text { conservação da água }\end{array}$ & $\mathrm{D}$ & MARIAO & 2017 \\
\hline $\begin{array}{l}\text { Cinema, educação e imaginários contemporâneos: estudos } \\
\text { hermenêuticos sobre distopia, niilismo e afirmação nos filmes } O \\
\text { som ao redor, O cavalo de Turim e Sono de inverno }\end{array}$ & A & ALMEIDA & 2018 \\
\hline $\begin{array}{l}\text { Guia de filmes para Educação Ambiental: ferramenta para } \\
\text { professores de ciências e biologia? }\end{array}$ & $\mathrm{D}$ & RODRIGUES & 2018 \\
\hline $\begin{array}{l}\text { A - Artigo; D - Dissertação; M - Mo } \\
\text { Fonte: Organizado pelo autor. }\end{array}$ & & & \\
\hline
\end{tabular}

Entre os artigos científicos observa-se o trabalho de Almeida (2018), que estudou a relação entre cinema, educação e imaginários contemporâneos analisando 3 filmes; Guimarães e Fantin (2016), que fazem uma análise do cinema de animação como objeto de conhecimento, construção de identidades sociais e culturais e como instrumento pedagógico; Anjos e Santos (2017), 
estudaram o potencial pedagógico do filme Bambi; Amaral (2013) estudou o filme FormiguinhaZ para avaliar a representação dos caracteres biológicos e sua relação com a linguagem científica; Franco et al (2013) e Oliveira et al (2016) analisaram o filme Vida de Inseto e a forma como apresenta caracteres ecológicos relacionados aos insetos para uso como ferramenta pedagógica. Da-Silva e Coelho (2016) exploram o uso de caracteres zoológicos para composição de personagens da cultura Pop e o uso desses personagens na educação regular; Santos e Piassi (2010) discutem a presença dos temas transversais no filme Wall-E; e Hoppe (2017) aborda o papel da educomunicação para discussão de temáticas ambientais utilizando o filme Lorax - em busca da trúfula perdida.

Além destes, Bastiani e Rosa (2012) estudaram a relação entre filosofia e Educação Ambiental através da animação; Silva et al (2016) analisaram a exploração de questões sociocientíficas em filmes de animação; Guido e Buzzo (2011) discutem a categorização do cinema e a importância para a Educação Ambiental; Guimarães e Fantin (2016) discutiram a inserção do cinema de animação em diferentes espaços formativos; Barros et al. (2013) investigaram a percepção de professores sobre o uso do cinema como recurso pedagógico; Esperança e Dias (2008) evidenciam a relação entre mídias e educação infantil; Gomes e Santos (2007) discutem as estratégias linguísticas presentes nos filmes de animação; Machado (2008) alerta para a importância dos filmes de ficção científica para fins pedagógicos; Costa e Barros (2014) investigam a importância do cinema no ensino de ciências e biologia; enquanto Vieira e Rosso (2011) analisam o cinema e suas potencialidades pedagógicas.

Se comparado ao quantitativo de publicações de outra natureza, o número de artigos é mais expressivo, representando $51 \%$ do total de produções, e levando em consideração que essa lista pode ser maior se a busca for ampliada em relação à janela temporal ou mesmo a partir da busca em outros bancos de indexação nacionais e internacionais. Esse quantitativo, aliado às suas características auditáveis, fez com que apenas os artigos fossem considerados para composição da fundamentação teórica deste trabalho.

Quanto a lista de artigos publicados em revistas científicas entre 2007 e 2018 (Figura 1), observa-se que o maior número de publicações ocorreu em 2009, 2013, 2016 e 2017, com 3, 4, 4 e 3 artigos, respectivamente. Período em que aconteceram lançamentos de filmes ou suas continuidades, como Avatar (2009), Wall-E (2008), A Era do Gelo (2009/2012/2016), Rio (2011/2014), Lorax: em busca da trúfula perdida (2012) e Madagascar (2012/2014/2018). Com destaque para os filmes Wall-E, Lórax: em busca da trúfula perdida, Rio e Vida de Inseto que foram objetos de estudo nos artigos listados nesta pesquisa. 


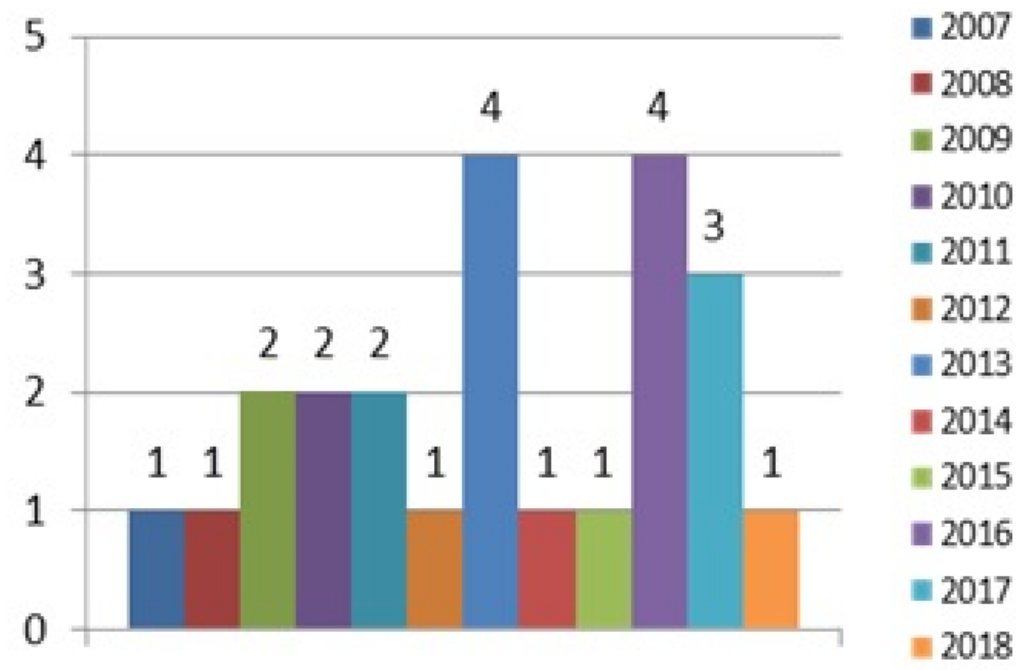

Figura 1: Frequência de artigos publicados entre 2007 e 2018. Fonte: organizado pelo autor.

\section{Conclusões}

O número de publicações encontradas é expressivo e a partir delas é possível desenhar o estado da arte no que diz respeito à compreensão da relação entre cinema de animação e Educação Ambiental. Além disso, o conjunto de publicações fornece contribuições importantes para o entendimento do diálogo entre esse gênero cinematográfico e a prática pedagógica, além de fornecer subsídios para fomentar outros estudos da mesma natureza.

Partindo desses pressupostos e considerando que a geração atual está cada vez mais conectada ao audiovisual, às plataformas de armazenamento e reprodução de áudio e vídeo, e às provedoras de filmes e séries via streaming, vinculadas à rede de internet, onde muitos dos filmes de animação estão inseridos, tornando-os elementos e ferramentas importantes e acessíveis para a concepção de estratégias didáticas em Educação Ambiental. Principalmente para o público infanto-juvenil, que a depender da forma como os conteúdos são apresentados, e dos recursos e estratégias linguísticas utilizadas, estabelecem conexões afetivas com os personagens e as histórias, que as potencializam como instrumentos de reflexão, ampliação da percepção e visão crítica sobre a relação do homem com ambiente e os recursos naturais.

O educador precisa levar em consideração que a liberdade dos roteiristas de criar e reproduzir ambientes e caracteres, sujeita as animações a leituras e percepções errôneas, extravagantes, distorcidas ou estereotipadas da realidade, que podem fomentar ou contribuir com a perpetuação de preconceitos e não servir às reflexões sobre a problemática ambiental, se o uso dessa ferramenta for negligenciado pelo educador com distanciamento da linguagem científica ou dos objetivos propostos no planejamento. 
Sendo assim, os resultados desta pesquisa contribuem para ampliar a utilidade didática das obras cinematográficas, como constatado em outros estudos, e demonstra que a utilização dos filmes de animação para fins pedagógicos é eficiente e pode enriquecer e potencializar ações educativas direcionadas ao combate do analfabetismo ambiental, desde que a linguagem fílmica seja cuidadosamente explorada na situação didática proposta para fomentar reflexões.

\section{Referências}

ABREU, C. S. Filmes de animação como recurso didático: Uma proposta para o professor. 2010. 65f. Monografia (Curso de Ciências Biológicas) - Instituto de Biologia, Universidade do Estado do Rio de Janeiro. Disponível em: http://www.decb.uerj.br/arquivos/monografias/Camila\%20Saboia.pdf Acesso em: 09/10/2018.

ALMEIDA, R. Cinema, educação e imaginários contemporâneos: estudos hermenêuticos sobre distopia, niilismo e afirmação nos filmes $O$ som ao redor, O cavalo de Turim e Sono de inverno. Educação e Pesquisa, v.44, e 175009, p.1-18, 2018.

AMARAL, T. Aspectos morfológicos, biológicos e comportamentais de insetos: entre a literatura entomológica e a recriação fílmica. Anais do 1ำ Simpósio Brasileiro de Entomologia Cultural. 2013. Disponível em: https://www.academia.edu/6566955/Anais do I Simp\%C3\%B3sio Brasileiro d e Entomologia Cultural 2013 Acesso em: 09/10/2018.

ARDENTE, N. C. A Utilização dos Filmes de Animação "Procurando o Nemo", "Os Sem Floresta" e "Vida de Inseto" como Recursos Didáticos no Ensino de Ciências. 2010. 47f. Monografia (Licenciatura em Ciências Biológicas) Departamento de Ensino de Ciências e Biologia, Universidade do Estado do Rio de Janeiro. Disponível em: http://www.decb.ueri.br/arquivos/monografias/ monografia licencNataliaArdente.pdf Acesso em: 09/10/2018.

BARROS, M. D. M.; GIRASSOLE, M.; ZANELLA, P. G. O uso do cinema como estratégia pedagógica para o ensino de ciências e de biologia: o que pensam alguns professores da região metropolitana de Belo Horizonte. Práxis, n.10, p.98-115, dez, 2013.

BASTIANI, T. M.; ROSA, M. B. Ética e Cinema: uma proposta interdisciplinar para a Educação Ambiental. Monografias Ambientais, v. 9, n. 9, p. 2072 2081, 2012.

CARVALHO, L. C.; REIS, M. S. A. O meio ambiente no filme de animação. Anais do XII Semana de Licenciatura, III Seminário de Pós-Graduação em Educação para Ciências e Matemática, e I Encontro de Egressos do Mestrado. IFGO. Jataí-GO, 2015. 
COLLA, R. A. Ecologização e convivialidade: aproximações entre a Educação Ambiental e o cinema. 2014. 103f. Dissertação (Mestrado em Educação) Programa de Pós-graduação em Educação, Pontífica Universidade Católica do Rio Grande do Sul. Disponível em: http://repositorio.pucrs.br/dspace/handle/1 0923/5698? locale=pt BR Acesso em: 10/10/2018

COSTA, E. C. P.; BARROS, M. D. M. Luz, câmera, ação: o uso de filmes como estratégia para o ensino de Ciências e Biologia. Práxis, n. 11, jun, 2014.

COSTA, E. C. P.; BARROS, M. D. M. Fantasia versus realidade: explorando as potencialidades do cinema para o ensino de Ciências e Biologia. Práxis, v.8, n. 1, p.27-35, Dez, 2016.

DA-SILVA, E. R.; COELHO, L. B. N. Zoologia Cultural, com ênfase na presença de personagens inspirados em artrópodes na cultura pop. Anais do III Simpósio De Entomologia do Rio de Janeiro. 2016. Rio de Janeiro. p.24-34 Disponível em: https://www.academia.edu/25180641/ZOOLOGIA CULTURAL COM \%C3\%8ANFASE NA PRESEN\%C3\%87A DE PERSONAGENS INSPI RADOS EM ARTR\%C3\%93PODES NA CULTURA POP Acesso em: 09/10/2018.

ESPERANÇA, J. A.; DIAS, C. M. S. Das infâncias plurais a uma única infância: mídias, relações de consumo e construção de saberes. Educação, v.33, n.1, p. 191-206, jan-abr, 2008.

FERREIRA, L. F. B. A narrativa cinematográfica alegórica/simbólica no cinema de animação. 2007. 220f. Dissertação (Mestrado em Artes) - Programa de Pós- Graduação em Artes, Universidade Federal de Minas Gerais. Disponível em: https://repositorio.ufmg.br/handle/1843/VPQZ-75VJ2P Acesso em: 10/10/2018.

FERREIRA, T. A. "Reflexões sobre cinema ambiental: uma abordagem multidisciplinar". 2013. 177f. Dissertação (Mestrado em Tecnologia e Inovação) - Programa de Pós-graduação em Tecnologia da Faculdade de Tecnologia, Universidade Estadual de Campinas. Disponível em: http://www.repositorio.unicamp.br/handle/REPOSIP/267759 Acesso em: 09/10/2018.

FRANCO, I. R.; SANTANA-REIS, V. P. G.; LOPES, P. P. A entomologia no cinema: análise do filme Vida de Inseto enquanto recurso didático. Anais do $1^{\circ}$ Simpósio Brasileiro de Entomologia Cultural. 2013.2 263-273. https://www.academia.edu/6566955/Anais do I Simp\%C3\%B3sio Brasileiro d e Entomologia Cultural 2013 Acesso em: 09/10/2018.

FRIEDRICH, S. P.; SANTOS, E. G.; GUT, M. Discutindo a Educação Ambiental em sala de aula sob o viés do filme Wall-E. Anais do II Congresso Internacional de Educação Cientifica e Tecnológica. 2012. 
GOMES, L. A. SANTOS, L. T. S. O Double Coding na Animação: A construção do Desenho Animado Contemporâneo para Adultos e Crianças. Revista Brasileira de Inovação Científica em Comunicação, v.2, n.2, p.74-81, 2007.

GUIDO, L. F. E.; BRUZZO, C. Apontamentos sobre o cinema ambiental: a invenção de um gênero e a Educação Ambiental. Revista Eletrônica do Mestrado em Educação Ambiental PPGEA/FURG-RS, v.27, p.57-68, jul-dez, 2011.

GUIMARÃES, L. B.; FANTIN, M. O cinema e os filmes de animação em contextos formativos. Educação em Foco v.21, v.1, p.141-156, mar-jun, 2016.

HOPPE, B. C. A. Educomunicação: um Estudo do Desenho de Dr. Seuss - O Lorax - Em Busca da Trúfula Perdida - Metáfora do Aproximar Homem e Natureza. Anais do 4ํ Congresso Internacional de Direito e Contemporaneidade. 2017. Santa Maria/RS. Disponível em: http://coral.ufsm.br/congresso direito/anais/2017/8-2.pdf Acesso em: 21/01/2019.

LISBOA, I. A. O uso do desenho animado como recurso didático - Filme Rio. 2012. 32f. Monografia (Licenciatura em Ciências Naturais) - Universidade de Brasília. Disponível: http://bdm.unb.br/bitstream/10483/4054/1/2012 laraAlves Lisboa.pdf Acesso em: 09/10/2018.

LORENZON, D.; SCHEID, N. M. J.; SOARES, B. M. Os filmes e os estudos de Educação Ambiental. Anais do IV Simpósio Nacional de Ensino de Ciência e Tecnologia. 2014. Disponível em: https://docplayer.com.br/14986004-Os-filmese-os-estudos-de-educacao-ambiental.html Acesso em: 15/11/2018.

LUVIELMO, M. M. Educação Ambiental, cinema e biopoder: Uma discussão possível. 2011. 88f. Dissertação (Mestrado em Educação Ambiental) Programa de Pós-graduação em Educação Ambiental, Universidade Federal do Rio Grande. Disponível em: http://repositorio.furg.br/handle/1/2232 Acesso em: 15/11/2018.

LUVIELMO, M. M.; LEIVAS, R. Z. Um Pedido de Socorro do Planeta Terra: Cinema de animação e Educação Ambiental. Revista Eletrônica do Mestrado em Educação Ambiental, v. 22, jan-jul, 2009.

MACHADO, C. A. Filmes de ficção científica como mediadores de conceitos relativos ao meio ambiente. Ciência e Educação, v. 14, n. 2, p.283-294, 2008.

MARCONI, M. A.; LAKATOS, E. M. Técnicas de Pesquisa. $7^{a}$ ed. São Paulo. Atlas: 2011.

MARIAO, F. R. Cinema como instrumento de sensibilização ambiental para conservação da água. 2017. 134f. Dissertação (Mestrado em Ciências Ambientais) - Programa de Pós-graduação em Ciências Ambientais, Universidade Federal de São Carlos. Disponível em: https://repositorio.ufscar.br/handle/ufscar/9522 Acesso em: 15/11/2018.

NETO, H. F. M. A semente de trúfula no solo da educação geográfica: pensamento ambiental e o cuidado com a terra em "The Lorax" de Dr. Seuss. Ciência Geográfica, v. 19, n. 1, p. 119-133, jan-dez, 2015.

revista brasileira educação ambiental 
OLIVEIRA, A. B. R.; HÖMANSEDER, B. M.; DA-SILVA, E. R.; COELHO, L. B. N. 2016. Análise do filme de animação "Vida de Inseto" à luz da Biologia Animal. Anais do III Simpósio de Entomologia do Rio de Janeiro. 2016. Rio de Janeiro. p.166-181. Disponível em: https://www.academia.edu/26287270/ An\%C3\%A1lise do Filme Vida de Inseto \%C3\%A0 luz da Biologia Animal .pdf Acesso em: 09/10/2018.

OTT, A. P.; CANDÉO, M. Ficção ou realidade: uma perspectiva do futuro do nosso planeta na visão infantil. Anais do II Simpósio Nacional de Ensino de Ciência e Tecnologia. n.149. 2010.

PENTEADO, R. Z.; COSTA, B. C. G.; RODRIGUES, P. H. G. N. Imaginários no cinema de animação: estetização de corpos na interface do cuidado de crianças e adolescentes. Saúde Soc, v.27, n.2, p. 381-397, 2018.

PIASSI, L. P.; PIETROCOLA, M. Ficção científica e ensino de ciências: para além do método de 'encontrar erros em filmes'. Educação e Pesquisa, v.35, n.3, p. 525-540, set-dez, 2009.

PINHEIRO, P. KINDEL, E. A. Debates sobre filmes infantis em sala de aula: uma ferramenta contra a posse de animais silvestres. Revista Eletrônica do Mestrado em Educação Ambiental PPGEA/FURG-RS, v.30, n. 2, p. 27-48, jul-dez, 2013.

REIS, M. A.; CARVALHO, L. C. O meio ambiente no filme infantil. Anais do XII Semana de Licenciatura. p.356-362. 2015.

RODRIGUES, M. A. R. S. Guia de filmes para Educação Ambiental: ferramenta para professores de ciências e biologia? 2018. Dissertação (Mestrado em Ensino de Ciências e Matemática) - Programa de Pós-graduação em Ensino de Ciências e Matemática, Universidade Federal de Uberlândia. Disponível em: https://repositorio.ufu.br/handle/123456789/22571 Acesso em: 09/10/2018.

SANTOS, E. G.; ANJOS, C. S. Potencialidades Pedagógicas do Filme Bambi no Ensino de Ecologia e Educação Ambiental. Revista de Educação, Ciência e Tecnologia, v.6, n.2, p 1-21, 2017.

SANTOS, F. R.; PIASSI, L. P. C. Wall-e: o uso do filme de animação na Educação Ambiental com temas transversais dos PCN. Anais do II Simpósio Nacional de Ensino de Ciência e Tecnologia. 2010. Disponível em: https://docplayer.com.br/7724301-Wall-e-o-uso-de-um-filme-de-animacao-naeducacao-ambiental-com-temas-transversais-dos-pcn.html Acesso em: 15/11/2018.

SANTOS, J. N. Manual de orientações: o filme como recurso didático nas aulas de ecologia. 2013. 84f. Dissertação (Mestrado em Ensino de Ciências) Programa de Pós-graduação em Formação Científica, Educacional e Tecnológica, Universidade Tecnológica Federal do Paraná. Disponível em: http://repositorio.utfpr.edu.br/jspui/handle/1/729 Acesso em: 10/10/2018. 
SILVA, M. M.; BARROS, M. D. M.; DE LA ROQUE, L. R. As questões sociocientíficas e a trama do filme Elysium: conexões entre ciência e cidadania no "chão" da escola. Demetra, v.12, n.3, p. 561-574, 2017.

SILVA, P. P. Percepções de estudantes do Ensino Médio noturno sobre representações de animais em desenhos animados. 2015. 61f. Monografia (Curso de Licenciatura em Ciências Biológicas) - Instituto de Biociências, Universidade Federal do Rio Grande do Sul. https://lume.ufrgs.br /handle/10183/142135 Acesso em: 09/10/2018.

SOUZA, F. R. Filmes nas salas de aula: as ciências em foco. 2012. $55 \mathrm{f}$. Monografia (Curso de Licenciatura em Ciências Biológicas) - Universidade Federal de Santa Catarina. Disponível em: http://www.periodicos.ulbra.br/ index.php/txra/article/view/927a Acesso em: 15/11/2018.

TAKADA, K. Arrival of the insect movie stars: Commentary on the animated movie "A Bug's Life" from the aspect of Cultural Entomology providing insight for instruction of entomological know ledge, insect conservation and management practic. In: 1 Simpósio Brasileiro de Entomologia Cultural. 2013. p.181-187. https://www.academia.edu/6566955/Anais do I Simp\%C3\% B3sio Brasileiro de Entomologia Cultural 2013 Acesso em: 09/10/2018.

VIEIRA, F. Z. A utilização didática do cinema para a aprendizagem da Educação Ambiental. 2009. 139f. Dissertação (Mestrado em Educação) Programa de Pós-graduação em Educação, Universidade Estadual de Ponta Grossa. Disponível em: https://tede2.uepg.br/ispui/bitstream/prefix/1294/1/ FernandoZan.pdf Acesso em: 10/10/2018.

VIEIRA, F. Z.; ROSSO, A. J. O cinema como componente didático da Educação Ambiental. Diálogo Educativo, v.11, n.33, p. 574-572, mai-ago, 2011.

VIZACHRI, T. R. Animais humanos ou humanos animais? Um estudo sobre a representação dos animais antropomorfizados nos filmes de animação. 2014. 137f. Dissertação (Mestrado em Filosofia) - Programa de Pós-graduação em estudos culturais, Universidade de São Paulo. Disponível em: https://teses.usp.br/teses/disponiveis/100/100135/tde-02122014-162925/ptbr.php Acesso em: 09/10/2018.

WOLFF, N. M. O. Filmes de animação infantil como ferramenta de Educação Ambiental. 2013. 42f. Monografia (Curso de Pós-graduação Lato Sensu em Interdisciplinaridade e Práticas Pedagógicas na Educação Básica) Universidade Federal da Fronteira Sul. Disponível em: https://rd.uffs.edu.br/ handle/prefix/264 Acesso em: 09/10/2018.

XAVIER, J. F. P. Uso do desenho animado como estratégia metodológica para a Educação Ambiental. 2008. 135f. Dissertação (Mestrado em Educação) Programa de Mestrado Acadêmico em Educação. Universidade do Vale do Itajaí. Disponível em: https://siaiap39.univali.br/repositorio/handle/repositorio/ 1765 Acesso em: 15/11/2018. 